\title{
Postprandial gallbladder emptying in patients with type 2 diabetes: potential implications for bile-induced secretion of glucagon-like peptide 1
}

\author{
David P Sonne ${ }^{1,2}$, Jens F Rehfeld ${ }^{3}$, Jens J Holst ${ }^{2}$, Tina Vilsbøll ${ }^{1,2}$ and Filip K Knop ${ }^{1,2}$ \\ ${ }^{1}$ Diabetes Research Division, Department of Medicine, Gentofte Hospital, University of Copenhagen, Niels \\ Andersens Vej 65, DK-2900 Hellerup, Denmark, ${ }^{2}$ The NNF Center for Basic Metabolic Research, \\ Department of Biomedical Sciences, The Panum Institute, University of Copenhagen, Copenhagen, \\ Denmark and ${ }^{3}$ Department of Clinical Biochemistry, Copenhagen University Hospital Rigshospitalet, \\ Copenhagen, Denmark
}

\author{
Correspondence \\ should be addressed \\ to D P Sonne \\ Email \\ dpsonne@gmail.com
}

\begin{abstract}
Objective: Recent preclinical work has suggested that postprandial flow of bile acids into the small intestine potentiates nutrient-induced glucagon-like peptide 1 (GLP1) secretion via bile acid-induced activation of the G protein-coupled receptor TGR5 in intestinal L cells. The notion of bile-induced GLP1 secretion combined with the findings of reduced postprandial gallbladder emptying in patients with type 2 diabetes (T2DM) led us to speculate whether reduced postprandial GLP1 responses in some patients with T2DM arise as a consequence of diabetic gallbladder dysmotility.

Design and methods: In a randomised design, 15 patients with long-standing T2DM and 15 healthy age-, gender- and BMI-matched control subjects were studied during 75-g oral glucose tolerance test (OGTT) and three isocaloric (500 kcal) and isovolaemic (350 ml) liquid meals: i) $2.5 \mathrm{~g}$ fat, $107 \mathrm{~g}$ carbohydrate and $13 \mathrm{~g}$ protein; ii) $10 \mathrm{~g}$ fat, $93 \mathrm{~g}$ carbohydrate and $11 \mathrm{~g}$ protein; and iii) $40 \mathrm{~g}$ fat, $32 \mathrm{~g}$ carbohydrate and $3 \mathrm{~g}$ protein. Basal and postprandial plasma concentrations of glucose, insulin, C-peptide, glucagon, GLP1, glucose-dependent insulinotropic polypeptide (GIP), cholecystokinin and gastrin were measured. Furthermore, gallbladder emptying and gastric emptying were examined.

Results: Gallbladder emptying increased with increasing meal fat content, but no intergroup differences were demonstrated. GIP and GLP1 responses were comparable among the groups with GIP levels being higher following high-fat meals, whereas GLP1 secretion was similar after both OGTT and meals.

Conclusions: In conclusion, patients with T2DM exhibited normal gallbladder emptying to meals with a wide range of fat content. Incretin responses were similar to that in controls, and an association with postprandial gallbladder contraction could not be demonstrated.

\section{Introduction}

It has been shown previously in 1983 that bile acids stimulated the release of gut glucagon-like immunoreactive materials in dogs (1). More recently, it has become clear that bile acids not only act as simple fat solubilisers in the digestive tract, but also represent complex hormonal metabolic integrators (2). The most important receptors activated by bile acids are the farnesoid X receptor - a receptor (expressed in high concentrations in the liver and intestines), which is implicated in glucose control - and the G protein-coupled cell membrane receptor TGR5 $(2,3)$. Interestingly, in enteroendocrine cells, TGR5 activation leads to the secretion of glucagon-like peptide 1 (GLP1) and (c) 2014 European Society of Endocrinology Printed in Great Britain
Published by Bioscientifica Ltd. 
possibly other L cell products (e.g. the other satiety hormone peptide YY), suggesting that bile acids may modulate glucose homoeostasis, appetite and body weight via TGR5 (2). GLP1 and glucose-dependent insulinotropic polypeptide (GIP) are incretin hormones and they act in concert to generate the so-called incretin effect (i.e. the augmentation of insulin secretion after oral administration compared with an isoglycaemic i.v. glucose stimulus (4)). Moreover, GLP1 has a range of additional effects including inhibition of glucagon secretion, appetite and gastric motility, all of which ultimately impact on glucose homoeostasis (5). Secretion of GLP1 is stimulated by the arrival of digested nutrients in the intestinal lumen (5). However, GLP1 is rapidly metabolised by the ubiquitous enzyme dipeptidyl peptidase 4 (DPP4), whereby the biological activity is abolished. In accordance, it is believed that afferent neurons in the intestinal mucosa mediate the major glucoselowering effect of GLP1 (5). The predominant, but not unchallenged, view on GLP1 secretion in patients with type 2 diabetes (T2DM) is that some, but not all, patients (6) have defective postprandial responses $(7,8,9,10)$, whereas levels during oral glucose tolerance tests (OGTTs) usually are comparable to controls $(11,12,13,14,15,16)$. As bile acids may influence nutrient-induced GLP1 secretion from the L cells (via TGR5), postprandial flow of bile from the gallbladder into the intestine may potentiate the postprandial L cell response. Conversely, gallbladder dysmotility - a common, albeit not consistent (17), finding in patients with T2DM $(18,19,20,21)$ - may result in impaired postprandial flow of bile into the intestine and subsequently reduced bile acid-induced TGR5 activation (22).

We hypothesised that patients with T2DM of relatively long duration ( $>5$ years) would be characterised by decreased postprandial gallbladder contraction (as shown in previous studies) and, consequently, reduced postprandial intestinal TGR5 activation, resulting in attenuated GLP1 responses compared with healthy age-, gender- and BMI-matched control subjects. According to this hypothesis, an impairment of postprandial GLP1 secretion following high-fat meal intake in patients with T2DM would not be evident during low-fat meals or oral glucose, which ostensibly do not stimulate gallbladder emptying to the same extent.

\section{Subjects and methods}

The protocol was approved by the Scientific-Ethical Committee of the Capital Region of Denmark (registration no. H-1-2011-008) and registered with the Danish Data Protection Agency (registration no. 2011-41-6274) and at
ClinicalTrials.gov (clinical trial reg. no. NCT01374594). The study was conducted according to the principles of the Helsinki Declaration II. Written informed consent was obtained from all participants.

\section{Study population}

Following screening for prespecified inclusion and exclusion criteria (see below), 15 patients with a mean diabetes duration of 7.5 years (range: 6-20) and 15 healthy age-, gender- and BMI-matched control subjects were included in the study (Table 1). At the screening visit, all potential subjects $(n=58)$ underwent a physical examination and had standard haematological and clinical biochemistry parameters measured. Exclusion criteria included acute or chronic illnesses (including hypercholesterolaemia), gallbladder disease, taking ongoing medication (which could not be paused for $12 \mathrm{~h}$ ), having first-degree relatives with diabetes (control group) and showing repeated abnormalities in haemoglobin, plasma liver enzymes (alanine or aspartate aminotransferase), creatinine concentration or urinary albumin-to-creatinine ratio. The diabetic group consisted of patients with non-insulin-requiring T2DM of relatively long duration ( $>5$ years) diagnosed according to the criteria of the World Health Organization (WHO). All patients underwent a $75 \mathrm{~g}$ OGTT (1-2 weeks before the first day of study). None of the patients suffered from any overt diabetic complications. Four patients received only dietary treatment, eight were also treated with metformin and three with sulphonylurea. Patients were instructed to avoid their blood glucose-lowering drugs, if any, for

Table 1 Characteristics of subjects. Data are mean values with ranges in parentheses.

\begin{tabular}{|c|c|c|}
\hline & Controls & T2DM \\
\hline Age (years) & $60(42-71)$ & $60(43-70)$ \\
\hline $\operatorname{Sex}(M / F)$ & $9 / 6$ & $9 / 6$ \\
\hline Height (m) & 1.76 (1.58-1.92) & $1.75(1.60-1.97)$ \\
\hline Weight (kg) & $86.5(66.0-106.0)$ & $85.9(63.6-121.5)$ \\
\hline BMI $\left(\mathrm{kg} / \mathrm{m}^{2}\right)$ & $27.9(24.0-31.7)$ & $28.0(24.5-31.9)$ \\
\hline Waist:hip ratio & $0.97(0.85-1.11)$ & $0.98(0.86-1.14)$ \\
\hline $\begin{array}{l}\text { Systolic blood pressure } \\
(\mathrm{mmHg})\end{array}$ & $127(110-142)$ & $133(109-168)$ \\
\hline $\begin{array}{l}\text { Diastolic blood } \\
\text { pressure }(\mathrm{mmHg})\end{array}$ & $81(62-88)$ & $82(66-97)$ \\
\hline $\begin{array}{l}\text { Fasting plasma glucose } \\
(\mathrm{mmol} / \mathrm{l})\end{array}$ & $5.3(4.8-6.0)$ & $10.2(6.3-15.5)$ \\
\hline HbA1c (\%) & $5.2(4.9-5.7)$ & $7.5(6.0-9.9)$ \\
\hline $\mathrm{HbA1c}(\mathrm{mmol} / \mathrm{mol})$ & 33 (30-39) & $58(42-85)$ \\
\hline $\begin{array}{l}\text { Duration of T2DM } \\
\text { (years) }\end{array}$ & - & $7.5(6-20)$ \\
\hline
\end{tabular}


a period of not less than a week before each experimental day (see below). Other medications included angiotensin II receptor blockers: 2; angiotensin-converting enzyme inhibitors: 7; calcium antagonists: 4; thiazide diuretics: 4; acetylsalicylic acid: 7; protein-pump inhibitors: 1; and statins: 13 . Control subjects were without family history of diabetes and had normal glucose tolerance according to a $75 \mathrm{~g}$ OGTT performed immediately before inclusion in the study. The control subjects were not taking any form of medication.

\section{Study design}

On all occasions, subjects were studied in a semi-recumbent position, lying on their backs with the upper part of the body $45^{\circ}$ upright, after an overnight $(10 \mathrm{~h})$ fast including liquids, medication and tobacco use. Subjects were instructed to avoid strenuous physical exercise for $12 \mathrm{~h}$ before arriving in the morning. The experiments were carried out for 4 days randomly, separated by at least $48 \mathrm{~h}$, and consisted of a $75 \mathrm{~g}$ OGTT (75 g of water-free glucose dissolved in $300 \mathrm{ml}$ water) and three isocaloric $(500 \mathrm{kcal})$ and isovolaemic $(350 \mathrm{ml})$ liquid meals (low fat: $2.5 \mathrm{~g}$ fat, $107 \mathrm{~g}$ carbohydrate and $13 \mathrm{~g}$ protein; medium fat: $10 \mathrm{~g}$ fat, $93 \mathrm{~g}$ carbohydrate and $11 \mathrm{~g}$ protein and high fat: $40 \mathrm{~g}$ fat, $32 \mathrm{~g}$ carbohydrate and $3 \mathrm{~g}$ protein). Meals were made by combining two nutritional drinks (Nutridrink Juice Style and Calogen Strawberry, Nutricia, Allerød, Denmark) and mixing them with $1.5 \mathrm{~g}$ paracetamol for evaluation of gastric emptying. The amount of fat in the meals was based on the threshold for effective fat-induced gallbladder contraction $(\sim 10 \mathrm{~g})$ (23). Water was added to standardise the volume to $350 \mathrm{ml}$. On each day, a cannula was inserted into a cubital vein for collection of arterialised blood samples (cannulated forearm was placed in a heating box $\left(50^{\circ} \mathrm{C}\right)$ throughout the experiment). The OGTT or meals were ingested over the first $10 \mathrm{~min}$ of the experiment (after baseline sampling).

\section{Data collection}

Arterialised blood samples were drawn 20, 10 and 0 min before and 15, 30, 45, 60, 90, 120, 180 and 240 min after ingestion of the OGTT or meals. Blood was collected into chilled tubes containing EDTA and a specific DPP4 inhibitor (valine pyrrolidide at a final concentration of $0.01 \mathrm{mmol} / \mathrm{l}$ ) for plasma analyses of gut hormones. For analyses of insulin and C-peptide, blood was distributed into chilled tubes containing heparin. EDTA and heparin tubes were kept on ice until centrifugation. Blood for analysis of paracetamol (acetaminophen) was distributed into dry tubes for coagulation (20 $\mathrm{min}$ at room temperature). All samples were centrifuged for $20 \mathrm{~min}$ at $1200 \boldsymbol{g}$ and $4{ }^{\circ} \mathrm{C}$. Plasma samples for GLP1, GIP, glucagon, cholecystokinin (CCK) and gastrin analyses and serum samples for paracetamol were stored at $-20^{\circ} \mathrm{C}$, and plasma samples for insulin and C-peptide analyses were stored at $-80{ }^{\circ} \mathrm{C}$ until analysis. For bedside measurements of plasma glucose, blood was distributed into fluoride tubes and centrifuged immediately at $7400 \mathrm{~g}$ for $2 \mathrm{~min}$ at room temperature.

Gallbladder measurements were performed using a Pro Focus ultrasound scanner (B\&K Medical, Herlev, Denmark) with a $3.5 \mathrm{MHz}$ convex transducer. The gallbladder was measured in three dimensions, one longitudinal (D1) and two cross-sectional diameters (D2 and $D 3$ ), and the volume was calculated using the ellipse formula (volume $=\pi / 6 \times D 1 \times D 2 \times D 3)(24)$. Basal gallbladder volumes were based on the average of two sequential measurements followed by measurements every $10 \mathrm{~min}$ for the first hour. A single investigator performed gallbladder measurements. Intraobserver variation of fasting images was within $10 \%$ (smallest when the gallbladder was large), which is in agreement with Everson et al. (25). Gallbladder ejection fraction (EF\%) was defined as the reduction in the gallbladder volume at any time point from baseline divided by the baseline gallbladder volume multiplied by $100 \%$. EF\% time curves were characterised descriptively by calculating the maximum response $\left(E_{\max }\right)$ and time to maximum response $\left(T_{\max }\right)$, and further by calculating the area under the curve (AUC) from 0-60 min, using the trapezoidal rule.

\section{Laboratory methods}

Plasma glucose was measured by the glucose oxidase method, using a glucose analyser (Yellow Springs Instrument model 2300 STAT plus analyzer; YSI, Inc., Yellow Springs, OH, USA). Plasma insulin and C-peptide concentrations were measured using a two-sided electrochemiluminescence immunoassay (Roche/Hitachi Modular analytics; Roche Diagnostic $\mathrm{GmbH})$. Intra- and interassay coefficient of variation $(\mathrm{CV})$ values are $<3 \%$ (insulin) and $<6 \%$ (C-peptide) respectively. Plasma concentrations of total GLP1, GIP, amidated gastrin and CCK were measured by RIAs as described previously $(26,27,28,29)$. Intra- and interassay CV values for GIP, GLP1 and glucagon are $<6$ and $<15 \%$ respectively. The glucagon assay was directed against the C-terminal of the glucagon molecule and, therefore, measures glucagon of 
pancreatic origin (14). For CCK and amidated gastrin, the intra- and interassay CV values are $<6$ and $<10 \%$ respectively. Serum paracetamol was measured by the Vitros ACET slide as described previously $(30,31)$. Intra- and interassay $\mathrm{CV}$ value for paracetamol is $<5 \%$.

\section{Statistical analyses}

Results are expressed as means \pm s.E.M. unless otherwise stated. The AUC values were calculated using the trapezoidal rule and are presented as incremental AUC (iAUC) values if nothing else is stated. For analysis of variations and differences between the AUC values, repeated measures ANOVA with Tukey's post hoc test was used. The assumptions of a Gaussian distribution of observations and homogeneity of variances were assessed visually by drawing histograms and probability plots. If assumptions could not be met, data were transformed logarithmically or reciprocally before statistical analysis was performed. A two-sided $P$ value of $<0.05$ was used to indicate significant differences. Statistical analyses were performed using GraphPad Prism version 6.0b for Windows/Mac (GraphPad Software, San Diego, CA, USA) and R (3.0.1) for Windows/Mac (http://cran.r-project.org).

\section{Results}

\section{Glucose}

Time courses for plasma concentrations of glucose are shown in Fig. 1 and the AUC values are given in Table 2. On all study days, mean fasting and postprandial plasma glucose concentrations were higher in patients compared with the control group. In both groups, postprandial glucose excursions were comparable following the OGTT, low-fat meal and medium-fat meal, but became markedly reduced in response to the high-fat meal.

\section{Insulin and C-peptide}

Time courses for plasma concentrations of insulin and C-peptide are shown in Fig. 1 and AUC values are given in Table 2. Basal concentrations of insulin and C-peptide, respectively, were slightly higher in patients with T2DM compared with controls, and during the first 90 min of the OGTT, low-fat meal and medium-fat meal (Fig. 1), the concentrations were markedly lower in patients when compared with controls $(P=0.001-0.005)$. By contrast, no intergroup differences were demonstrated comparing the responses after the high-fat meal $(P=0.16)$. In both groups, high fat resulted in very small increments of insulin and C-peptide concentrations (Fig. 1).

\section{Glucagon}

Basal concentrations of glucagon were higher in patients with T2DM compared with controls $(14.0 \pm 0.7$ vs $8.7 \pm$ $0.3 \mathrm{pmol} / 1 \times \min , P<0.0001)$. As illustrated in Fig. 1 , the glucagon concentrations were markedly augmented in patients with T2DM compared with controls. From 0-30 min, peak concentrations reached $\sim 20 \mathrm{pmol} / 1$ (OGTT) to $\sim 25 \mathrm{pmol} / \mathrm{l}$ (meals) in patients compared with a peak of $\sim 12 \mathrm{pmol} / \mathrm{l}$ in controls during the high-fat meal. Controls were capable of suppressing glucagon secretion during OGTT $(-134 \pm 40 \mathrm{pmol} / \mathrm{l} \times \mathrm{min})$, low-fat $(-45 \pm$ $52 \mathrm{pmol} / \mathrm{l} \times \mathrm{min})$ and medium-fat $(-19 \pm 32 \mathrm{pmol} / \mathrm{l} \times \mathrm{min})$ meals (Fig. 1 and Table 2), with greater suppression following OGTT in comparison with low- and medium-fat meals $(P=0.002-0.013)$. However, glucagon was augmented throughout following high-fat meals in controls (Fig. 1).

\section{GLP1 and GIP}

Time courses for plasma concentrations of GLP1 and GIP are shown in Fig. 2 and AUC values are given in Table 3 . Intergroup differences of peak values and iAUC values of both GLP1 and GIP were comparable (Table 2). On the contrary, within group comparisons in both groups revealed that the high-fat meal resulted in the highest peak and iAUC values $(P=0.0001-0.01)$. This was particularly clear for GIP, which increased with increasing fat content in the meals $(P<0.0001)$. Notably, following the high-fat meal, patients with T2DM exhibited earlier peak values of GIP $(\sim 30 \mathrm{~min})$ compared with controls ( $90 \mathrm{~min}$ ) (Fig. 2).

\section{CCK and gastrin}

Time courses for the plasma concentrations of CCK and gastrin are shown in Fig. 2 and AUC values are given in Table 3. Basal levels of CCK were comparable among patients with T2DM and controls on all study days $(0.7 \pm$ 0.03 vs $0.7 \pm 0.04 \mathrm{pmol} / 1 \times \min$, all days grouped). In controls, peak CCK concentrations were similar and no clear dose-response relationship towards augmented CCK responses with increasing fat content was indicated (Table 3). Patients with T2DM exhibited augmented meal CCK responses compared with the OGTT response (Table 3). The peak concentrations of CCK following medium- and high-fat meals were higher than those of 

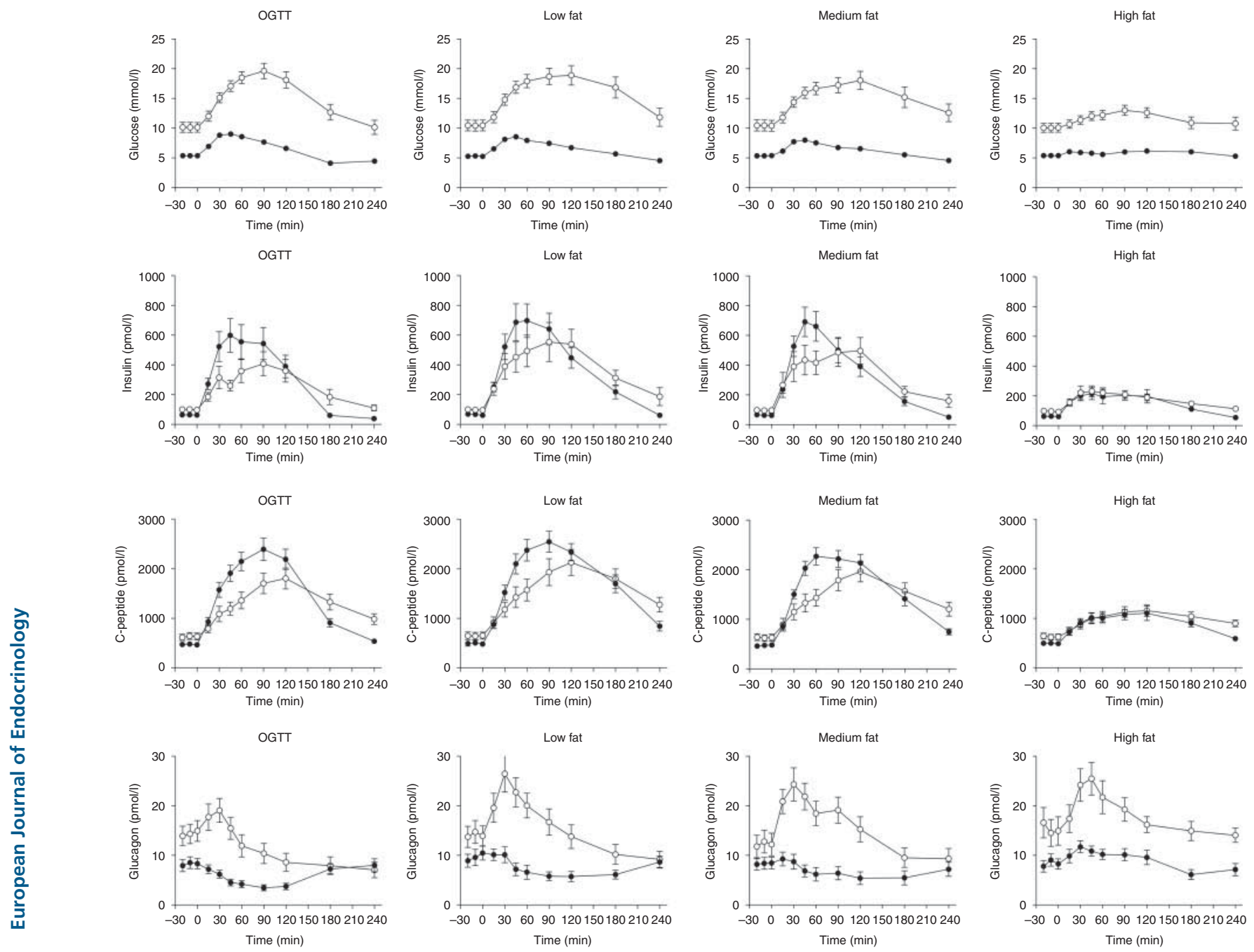

Figure 1

Plasma levels of glucose, insulin, C-peptide and glucagon during a $75 \mathrm{~g}$ OGTT and three isocaloric (500 kcal) and isovolaemic $(350 \mathrm{ml})$ liquid meals with low fat $(2.5 \mathrm{~g}$ fat, $107 \mathrm{~g}$ carbohydrate and $13 \mathrm{~g}$ protein), medium fat (10 $\mathrm{g}$ fat, $93 \mathrm{~g}$

OGTT and low-fat meals $(P<0.05)$. OGTT resulted in significantly higher $\mathrm{AUC}_{\mathrm{CCK}}$ values among controls compared with patients (Table 3). However, AUC $\mathrm{CCK}_{\text {values }}$ after meals were not significantly different between the two groups. Fasting concentrations of gastrin varied considerably among study days, but tended to be higher in patients compared with controls although statistical significance was only evident comparing medium and high fat (10.4 \pm 0.5 vs $6.4 \pm 0.5$ and $9.0 \pm 0.6$ vs $4.9 \pm 0.4 \mathrm{pmol} / \mathrm{l} \times \mathrm{min}$, $P<0.001$; Table 3 ). In patients with T2DM, gastrin responses following OGTT were similar to that of controls, but more robust and protracted following meals (Fig. 2).

carbohydrate and $11 \mathrm{~g}$ protein) and high fat (40 $\mathrm{g}$ fat, $32 \mathrm{~g}$ carbohydrate and $3 \mathrm{~g}$ protein) in patients with T2DM ( $n=15$, open symbols) and healthy control subjects ( $n=15$, closed symbols). Means ts.E.M. are shown.

However, statistical significance was only observed comparing iAUC values during the high-fat meal, although all meal peak values were higher in patients compared with controls (Table 3). All postprandial tAUC values of gastrin were higher in comparison with controls (Fig. 2).

\section{Gallbladder emptying}

EF\% time curves are depicted in Fig. 3 and calculations of gallbladder motility indices are given in Table 4 . In both groups, gallbladder contractility increased with increasing meal fat content $(P<0.001)$. Nevertheless, a comparable 

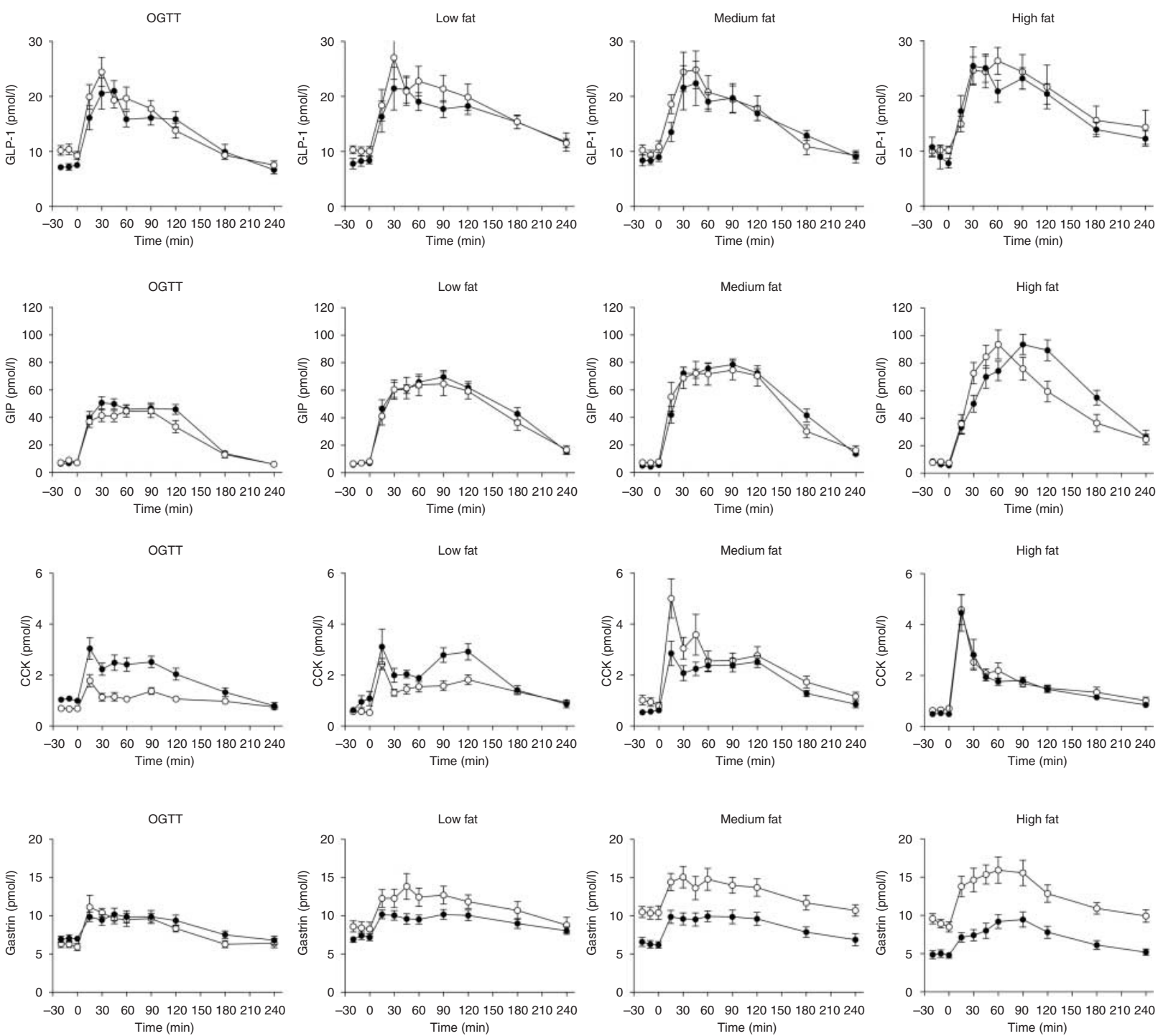

Figure 2

Plasma levels of GLP1, GIP, CCK and gastrin during a $75 \mathrm{~g}$ OGTT and three isocaloric (500 kcal) and isovolaemic $(350 \mathrm{ml})$ liquid meals with low fat $(2.5 \mathrm{~g}$ fat, $107 \mathrm{~g}$ carbohydrate and $13 \mathrm{~g}$ protein), medium fat (10 $\mathrm{g}$ fat, $93 \mathrm{~g}$ carbohydrate and

magnitude of gallbladder contraction was observed following the medium- and high-fat meals. No statistically significant intergroup differences were demonstrated in any of the calculated gallbladder motility indices (Table 4).

\section{Gastric emptying}

Time courses for the rate of gastric emptying are shown in Fig. 3 and calculations are given in Table 5. No intergroup
$11 \mathrm{~g}$ protein) and high fat ( $40 \mathrm{~g}$ fat, $32 \mathrm{~g}$ carbohydrate and $3 \mathrm{~g}$ protein) in patients with T2DM ( $n=15$, open symbols) and healthy control subjects ( $n=15$, closed symbols).

Means \pm s.E.M. are shown.

difference in gastric emptying was demonstrated after low- or medium-fat meals (Table 5). However, as indicated by time-to-peak values, gastric emptying following OGTT or high-fat meals was significantly faster in patients with T2DM compared with controls.

\section{Discussion}

The reported role of bile-induced TGR5 activation in L cell secretion combined with previous findings of reduced 


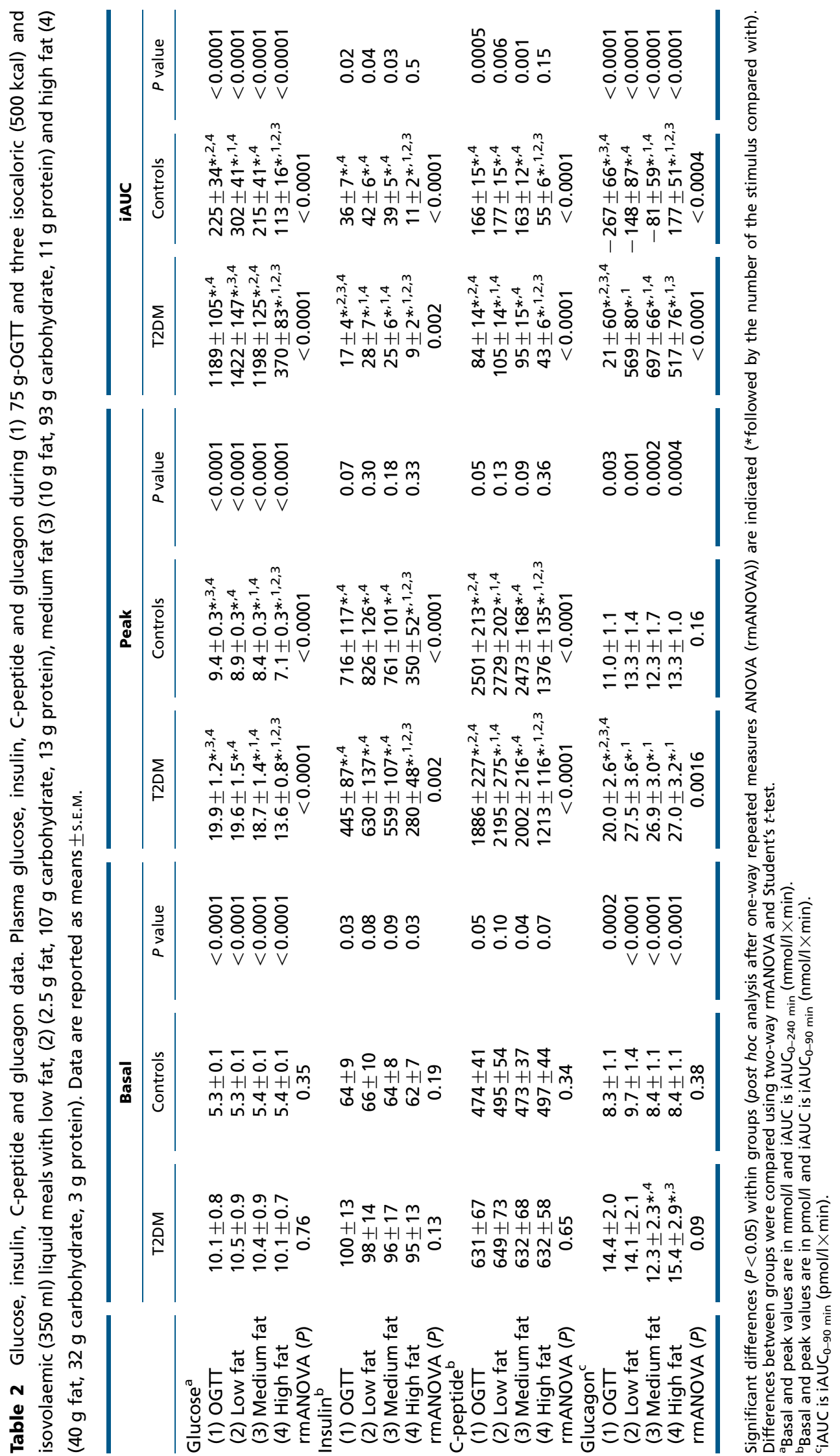




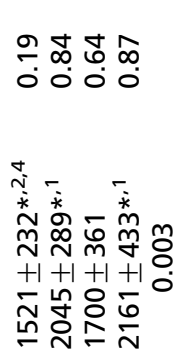

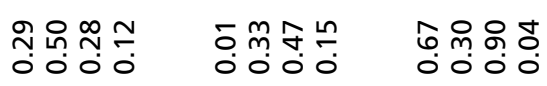

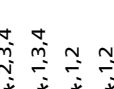

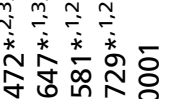

$n$
$+1+1+1+1$

$\bar{\pi}$

느늠

$m^{*} \bar{i}$ $m \stackrel{m}{m} \underset{m}{m} \quad \infty \infty_{\infty}^{m} \infty$ 8 욘

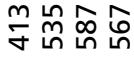

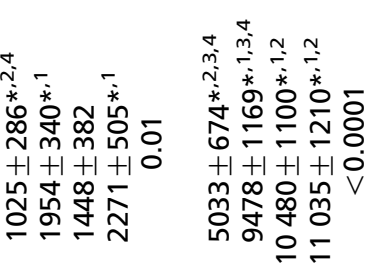

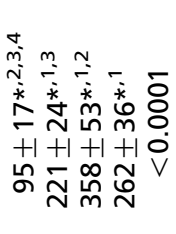

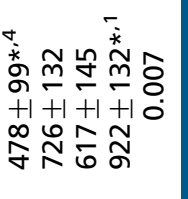

ㅇํำ ํํำ

욘ำ

ঠั ᄋ

웡

o 000

०000

○ं 0 ○ั

$\circ 000$

เก

i m $\dot{m} \sim$

$+\infty-\infty$.

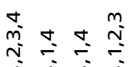

苾荠蓄离

$+1+1+1+10$

กั่

约过官它

mํํㅇํㅇ

$+1+1+1+10$

n m 6

$\dot{m} \dot{\sim} \dot{r} \dot{\sigma}$

ํㅜㅇㅇํㅇํํ

$+1+1+1+10$

뜸음

\section{ก $\infty \quad 0 \%$ \\ $+1+1+1+10$ \\ iे}

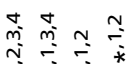

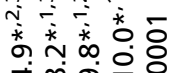

$+\infty$
$+1+1+1+1$
0

约

เทั

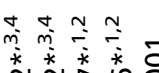

ペ

200
$+1+1+1+10$

六余宇

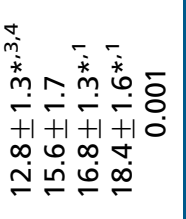

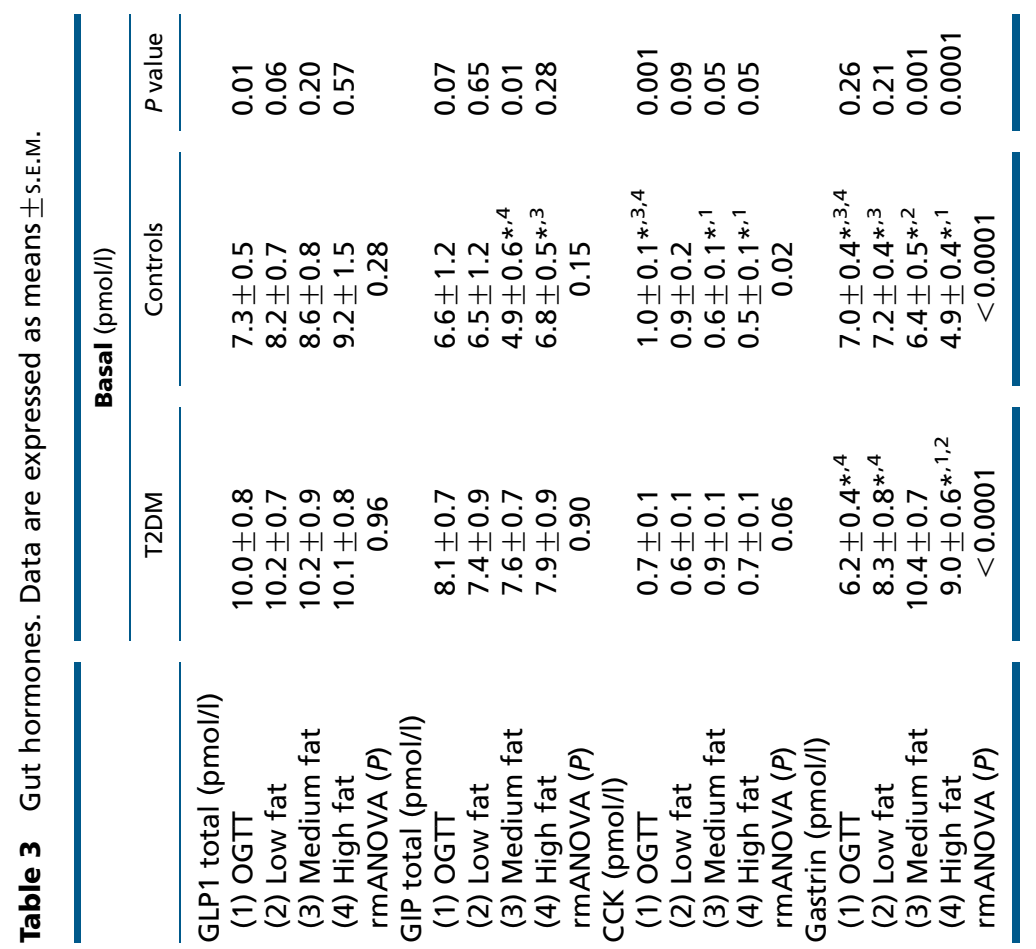

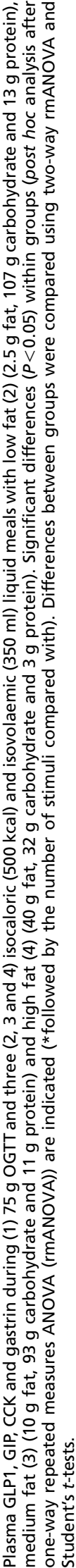



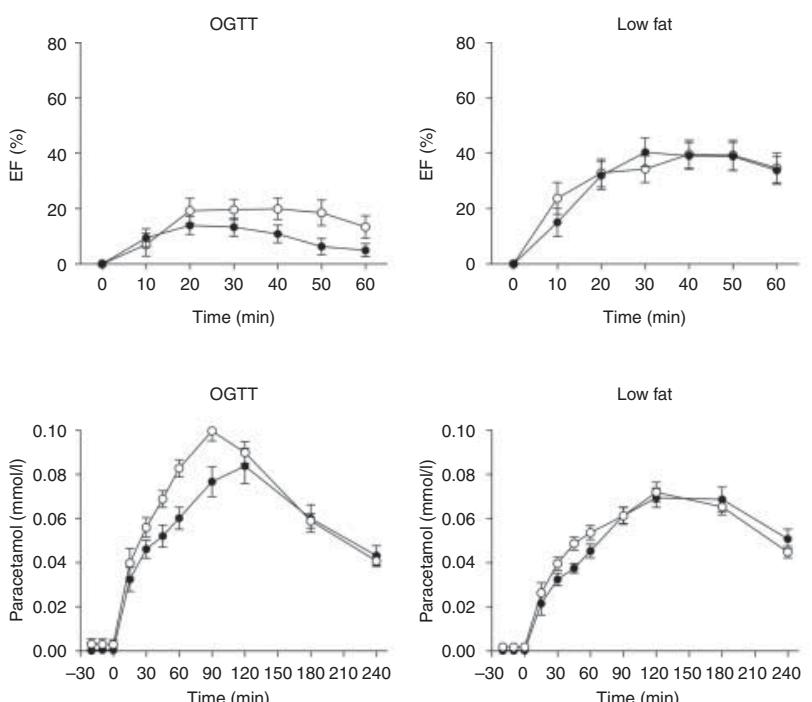

\section{Figure 3}

Gallbladder ejection fraction (EF\%) and gastric emptying (serum paracetamol) during a $75 \mathrm{~g}$ OGTT and three isocaloric (500 kcal) and isovolaemic $(350 \mathrm{ml})$ liquid meals with low fat ( $2.5 \mathrm{~g}$ fat, $107 \mathrm{~g}$ carbohydrate and $13 \mathrm{~g}$ protein), medium fat

postprandial gallbladder emptying in patients with T2DM $(18,19)$ prompted us to hypothesise that gallbladder dysmotility associated with T2DM with less flow of bile into the small intestine and, thereby, reduced activation of TGR5 on L cells might explain the lower postprandial GLP1 responses frequently reported in patients with T2DM. We also hypothesised that oral glucose would not affect gallbladder emptying noticeably in either healthy subjects or patients with T2DM and thereby explain the, often intact (or even exaggerated), postOGTT GLP1 responses in T2DM. Finally, we aimed to address whether the pathophysiology of T2DM
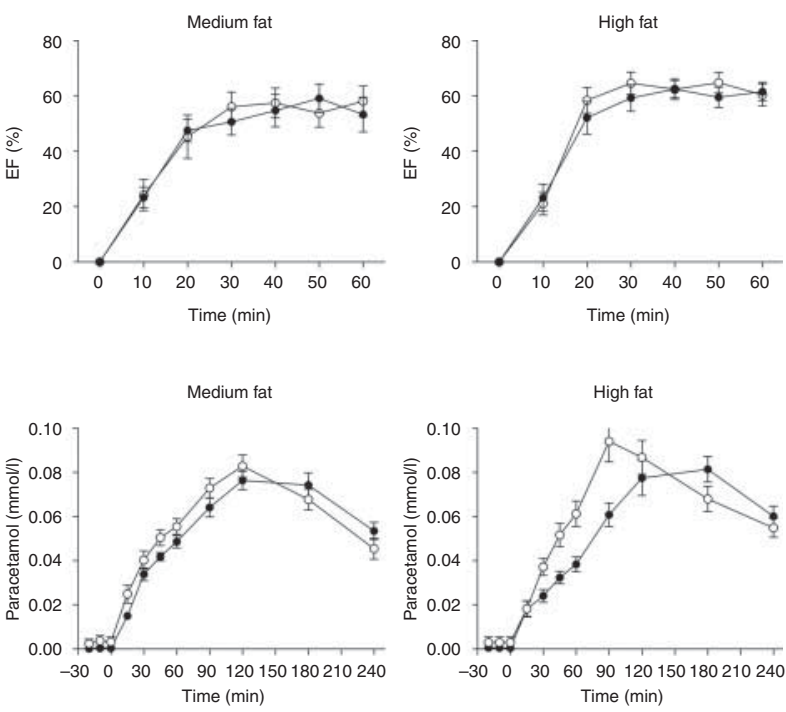

(10 g fat, $93 \mathrm{~g}$ carbohydrate and $11 \mathrm{~g}$ protein) and high fat (40 $\mathrm{g}$ fat, $32 \mathrm{~g}$ carbohydrate and $3 \mathrm{~g}$ protein) in patients with T2DM ( $n=15$, open symbols) and healthy control subjects ( $n=15$, closed symbols). Means \pm s.E.M. are shown.

encompasses reduced nutrient-induced GLP1 secretion, which, as noted, is still a subject of debate (6).

Our study illustrates that in both healthy subjects and patients with T2DM, gallbladder emptying increased with increasing meal fat content (Fig. 3). Unexpectedly, however, patients with T2DM did not exhibit any signs of reduced gallbladder motility as reported previously $(18,19,20,21)$. Hence, it seems unlikely that a difference in gallbladder emptying is of relevance to the variability of GLP1 responses observed in patients with T2DM, acknowledging that this study design and the relatively low numbers of patients in our study do not allow causal inferences in this regard.

Table 4 Gallbladder motility indices measured as gallbladder ejection fraction (EF\%). Data are presented as mean \pm S.E.M.

\begin{tabular}{|c|c|c|c|c|c|c|c|c|c|}
\hline & \multicolumn{3}{|c|}{$E_{\max }$} & \multicolumn{3}{|c|}{$\mathbf{T E}_{\max }(\min )$} & \multicolumn{3}{|c|}{$A C_{0-60} \mathrm{~min}$} \\
\hline & T2DM & Controls & $P$ value & T2DM & Controls & $P$ value & T2DM & Controls & $P$ value \\
\hline \multicolumn{10}{|c|}{ Gallbladder emptying (EF\%) } \\
\hline (1) OGTT & $32 \pm 4^{*, 2,3,4}$ & $23 \pm 3^{*, 2,3,4}$ & 0.08 & $32 \pm 3$ & $27 \pm 3^{*, 2,4}$ & 0.34 & $910 \pm 130 *, 2,3,4$ & $563 \pm 111 *, 2,3,4$ & $<0.06$ \\
\hline (2) Low fat & $50 \pm 4 *, 1,3,4$ & $49 \pm 4 *, 1,3,4$ & 0.83 & $41 \pm 3$ & $43 \pm 3 *, 1$ & 0.55 & $1873 \pm 234 * 1,3,4$ & $1823 \pm 217 * 1,3,4$ & $<0.87$ \\
\hline (3) Medium fat & $64 \pm 5 *, 1,2$ & $64 \pm 4 *, 1,2$ & 0.99 & $41 \pm 4$ & $42 \pm 4$ & 0.90 & $2659 \pm 290 *, 1,2$ & $2620 \pm 216^{*, 1,2}$ & $<0.92$ \\
\hline (4) High fat & $73 \pm 3 *, 1,2$ & $70 \pm 3 *, 1,2$ & 0.59 & $40 \pm 4$ & $45 \pm 3 *, 1$ & 0.28 & $3016 \pm 173 *, 1,2$ & $2874 \pm 196 * 1,2$ & $<0.59$ \\
\hline rmANOVA $(P)$ & $<0.0001$ & 0.0004 & & 0.21 & 0.005 & & $<0.0001$ & $<0.0001$ & \\
\hline
\end{tabular}

Gallbladder motility indices (paracetamol absorption) during (1) $75 \mathrm{~g}$ OGTT and three (2, 3 and 4) isocaloric (500 kcal) and isovolaemic (350 ml) liquid meals with low fat (2) (2.5 g fat, $107 \mathrm{~g}$ carbohydrate and $13 \mathrm{~g}$ protein), medium fat (3) (10 g fat, $93 \mathrm{~g}$ carbohydrate and $11 \mathrm{~g}$ protein) and high fat (4) (40 g fat, $32 \mathrm{~g}$ carbohydrate and $3 \mathrm{~g}$ protein). Significant differences $(P<0.05)$ within groups (post hoc analysis after one-way repeated measures ANOVA (rmANOVA)) are indicated (*followed by the number of stimuli compared with). Differences between groups were compared using two-way rmANOVA and Student's $t$-tests. 
Table 5 Gastric emptying measured as paracetamol absorption during $75 \mathrm{~g}$ OGTT and three isocaloric and isovolaemic liquid meals with low fat ( $2.5 \mathrm{~g}$ fat, $107 \mathrm{~g}$ carbohydrate and $13 \mathrm{~g}$ protein), medium fat (10 g fat, $93 \mathrm{~g}$ carbohydrate and $11 \mathrm{~g}$ protein) and high fat (40 $\mathrm{g}$ fat, $32 \mathrm{~g}$ carbohydrate and $3 \mathrm{~g}$ protein). Data are presented as mean \pm s.E.M.

\begin{tabular}{|c|c|c|c|c|c|c|c|c|c|}
\hline & \multicolumn{3}{|c|}{ Basal $(\mathrm{mmol} / \mathrm{l})$} & \multicolumn{3}{|c|}{ Peak (mmol/l) } & \multicolumn{3}{|c|}{ iAUC $_{\mathbf{0 - 2 4 0} \min }(\mathrm{mmol} / \mathrm{l} \times \mathrm{min})$} \\
\hline & T2DM & Controls & $P$ value & T2DM & Controls & $P$ value & T2DM & Controls & $P$ value \\
\hline \multicolumn{10}{|c|}{ Paracetamol $(\mathrm{mmol} / \mathrm{l})$} \\
\hline (1) OGTT & $0.102 \pm 0.005^{*, 2,3}$ & $0.085 \pm 0.008$ & 0.07 & $95 \pm 7^{*, 2,3}$ & $112 \pm 4^{*, 3,4}$ & 0.03 & $14.2 \pm 1.3$ & $15.4^{*, 2,3}$ & 0.41 \\
\hline (2) Low fat & $0.074 \pm 0.004^{*, 1,3,4}$ & $0.075 \pm 0.005^{*} .4$ & 0.86 & $140 \pm 11 *, 1$ & $137 \pm 12$ & 0.87 & $12.9 \pm 0.8$ & $12.8 * 1,4$ & 0.92 \\
\hline $\begin{array}{l}\text { (3) Medium } \\
\text { fat }\end{array}$ & $0.087 \pm 0.005^{*, 1,2}$ & $0.080 \pm 0.005^{*, 4}$ & 0.38 & $127 \pm 10^{*}$ & $144 \pm 8^{*, 1}$ & 0.19 & $13.8 \pm 0.8$ & $13.6 *, 1$ & 0.86 \\
\hline $\begin{array}{l}\text { (4) High fat } \\
\text { rmANOVA }(P)\end{array}$ & $\begin{array}{c}0.105 \pm 0.008^{* 1,2} \\
0.0014\end{array}$ & $\begin{array}{c}0.091 \pm 0.006^{*, 2,3} \\
0.064\end{array}$ & 0.16 & $\begin{array}{r}118 \pm 13 \\
0.007\end{array}$ & $\begin{array}{c}154 \pm 11^{*, 1} \\
0.006\end{array}$ & 0.04 & $\begin{array}{c}13.9 \pm 0.8 \\
0.35\end{array}$ & $\begin{array}{l}14.8^{\star, 2} \\
0.002\end{array}$ & 0.47 \\
\hline
\end{tabular}

Significant differences $(P<0.05)$ within groups (post hoc analysis after one-way repeated measures ANOVA (rmANOVA)) are indicated (*followed by the number of stimuli compared with). Differences between groups were compared using two-way rmANOVA and Student's $t$-tests.

However, in a previous study, we found that cholecystectomised patients exhibited preserved postprandial GLP1 responses compared with matched healthy controls, thus confirming that gallbladder contraction is not a prerequisite for postprandial GLP1 release (32). In terms of incretin responses, we show that GLP1 levels increased comparably following OGTT $(\sim 300 \mathrm{kcal})$ and meals of a wide range of nutrient composition ( $\sim 500 \mathrm{kcal})$. By contrast, postprandial GIP responses were higher compared with OGTT and were further augmented with the increasing fat content of the meals, confirming the important physiological role of fat in GIP release as demonstrated previously in obese (33) as well as lean subjects (34).

Both reduced, normal and increased GLP1 and GIP responses have previously been observed in patients with T2DM, but studies are difficult to compare (6) and only few studies directly assess incretin responses following both OGTT and meals in T2DM vs matched controls $(16,35)$. Possibly, our findings of similar incretin responses reflect the disease duration, as deteriorating glycaemic control might impair L cell secretion only in long-standing disease, but our results may also reflect the careful matching of patients and controls in terms of factors that modulate incretin release (6). Metformin use (eight patients) could have masked the defects in L cell secretion (36); however, we applied a washout period of 7 days for antidiabetic medications to ensure that metformin use would not result in carry-over stimulatory effects on GLP1 secretion. Thus, in these studies we did not find reduced postprandial GLP1 secretion during oral or liquid meal tests (in line with a recent meta-analysis of GLP1 responses in patients with T2DM and healthy control subjects (6)). This may be because of the small sample size and the fact that some of our patients had only mild diabetes and were not particularly obese. In a recent study of twin pairs discordant for obesity, liver fat and insulin resistance, a defective GLP1 response emerged concomitantly with increase in liver fat, insulin resistance and, ultimately, obesity (37).

In both groups, insulin levels were only modestly augmented, and strikingly similar, following the high-fat meal, despite high incretin levels, which might reflect incretin effects glucose dependency, although both GIP and GLP1 have been shown to increase insulin secretion at the given glycaemic levels (38). Notably, recent studies have suggested that incretins may also contribute to the islet response to fat and protein, although responses including plasma concentrations of glucose and lipids correlate poorly with insulin levels $(34,39)$. These findings might suggest that the primary role of GLP1 and GIP as mediators of insulin release after pure fat and protein ingestion is negligible. By contrast, under normal physiological circumstances, GIP and GLP1 seem to influence the insulinotropic capability of whey proteins and various amino acids $(40,41)$. Moreover, although lipids may stimulate insulin secretion directly (42), it has been recently shown that lipids evoke a similar incretin effect as is known for glucose (39). Notably, this is also evident for amino acids (43). Thus, the idea of widening the definition of the incretin concept, involving also noncarbohydrate macronutrients, is intriguing, although other insulin-stimulating factors may be involved such as direct effects of nutrients on the islet cells, neural factors or other gut hormones affecting insulin release $(33,34)$.

The fact that, in controls, glucagon secretion increased with increasing fat content in the meal is in keeping with the relatively recent finding that lipids stimulate glucagon secretion (34). This may be owing to GIP-induced glucagon secretion, and low glucose and 
insulin levels during the high-fat meal might also have played a role (44). In patients with T2DM, who were characterised by massive glucagon hypersecretion, nutrient composition in meals did not give rise to different glucagon profiles, suggesting that meal calories rather than composition is the prime regulator of postprandial glucagon secretion in patients with T2DM.

Our observation of preserved gallbladder emptying in patients with T2DM is in contrast to the majority of studies of gallbladder function in T2DM $(17,18,19)$. However, some studies report preserved gallbladder emptying, but deviate from this study in terms of patient selection, control group, methods of investigation and stimuli used for inducing gallbladder contraction $(17,45)$. To provide an explanation for this disparity, it is relevant to review our selection of patients with T2DM. These were broad representatives for a dysregulated population of patients with T2DM (HbA1c $>7 \%$, disease duration $>5$ years), but without clinical signs of autonomic neuropathy. Our choice of patients was based on the fact that in several studies reporting impaired gallbladder emptying in diabetic populations, the relationship to autonomic neuropathy has been subtle $(17,18,45)$. Other 'diabetic' factors may be of greater importance for diabetic gallbladder dysmotility (17). For example, high plasma glucose levels decrease the sensitivity of the smooth muscles of the gallbladder to circulating CCK $(46,47)$. Furthermore, hyperglycaemia may suppress cholinergic activity, and thus dampen the neural part of CCK-induced gallbladder emptying $(48,49)$. Thus, we believe that the patients included in our study were good representatives of the 'typical' phenotype of T2DM having a high risk of gallbladder dysmotility. Nevertheless, we cannot completely exclude the possibility of random sampling having resulted in the inclusion of T2DM patients with normal gallbladder function. Another explanation might be rooted in the rate of gastric emptying in the patients. In this study, we observed both normal (low- and medium-fat meals) and increased (OGTT and high-fat meal) gastric emptying in patients with T2DM compared with healthy controls. As gastric emptying determines nutrient delivery into the small intestine and thereby the release of CCK and GLP1, it is likely that the gallbladder contracts sufficiently despite the presence of some of the inhibitory factors mentioned above. Finally, methodological issues could have played a role, as the impairment of gallbladder emptying in the diabetic patients might have been too small for proper ultrasound assessment. Indeed, even relatively large impairments of gallbladder emptying, assessed by cholescintigraphy, can be overlooked by ultrasound assessment (17). However, in this study, the method was sensitive enough to detect differences following the different meal stimuli.

Our results on gastric emptying and gallbladder motility may reflect the impairment (responsiveness or secretion) of gut hormones that are important for intestinal motor function (i.e. motilin, CCK and GLP1). Low postprandial CCK concentrations have been reported in patients with T2DM (50). This may result in accelerated gastric emptying (and slowing of gallbladder emptying), and thus worsen postprandial hyperglycaemia. In this study, postprandial CCK concentrations were slightly lower in the diabetic group, but only following oral glucose (Fig. 2). To our knowledge, reduced CCK responses after glucose stimuli - together with the finding of similar gastrin responses - have never previously been reported in patients with T2DM.

In conclusion, our patients with T2DM exhibited normal gallbladder emptying to meals with a wide range of fat content. After both OGTT and meals, no evidence of a secretory defect in incretin secretion in patients with T2DM was observed. In both groups, postprandial incretin responses were unaffected by gallbladder emptying. Therefore, postprandial flow of bile from the gallbladder into the intestine is not likely to play a physiological role in potentiating the L cell response (via TGR5) in humans.

\section{Declaration of interest}

The authors declare that there is no conflict of interest that could be perceived as prejudicing the impartiality of the research reported.

\section{Funding}

This work was supported by an unrestricted grant from the Novo Nordisk Foundation.

\section{Author contribution statement}

D P Sonne contributed to the study design, clinical experiments, data research, statistical analysis and drafting manuscript. J F Rehfeld performed measurement of cholecystokinin and gastrin, data research, and review and editing of the manuscript. J J Holst performed measurement of incretin hormones and glucagon, and review and editing of the manuscript. T Vilsbøll reviewed and edited the manuscript. F K Knop contributed to the study design, and review and editing of the manuscript. All authors have read and approved the final version of the manuscript.

\section{Acknowledgements}

The authors are grateful to our volunteers whose availability made this work possible and to J Purtoft, N Kjeldsen, S Pilgaard Olesen, L Albæk, $\mathrm{J}$ Jagtboe and R Kröncke for their expert technical assistance. 


\section{References}

1 Namba M, Matsuyama T, Nonaka K \& Tarui S. Effect of intraluminal bile or bile acids on release of gut glucagon-like immunoreactive materials in the dog. Hormone and Metabolic Research 198315 82-84. (doi:10.1055/s-2007-1018635)

2 Thomas C, Gioiello A, Noriega L, Strehle A, Oury J, Rizzo G, Macchiarulo A, Yamamoto H, Mataki C, Pruzanski M et al. TGR5-mediated bile acid sensing controls glucose homeostasis. Cell Metabolism 200910 167-177. (doi:10.1016/j.cmet.2009.08.001)

3 Lefebvre P, Cariou B, Lien F, Kuipers F \& Staels B. Role of bile acids and bile acid receptors in metabolic regulation. Physiological Reviews 2009 89 147-191. (doi:10.1152/physrev.00010.2008)

4 Nauck M, Stöckmann F, Ebert R \& Creutzfeldt W. Reduced incretin effect in type 2 (non-insulin-dependent) diabetes. Diabetologia 198629 46-52. (doi:10.1007/BF02427280)

5 Holst JJ. The physiology of glucagon-like peptide 1. Physiological Reviews 200787 1409-1439. (doi:10.1152/physrev.00034.2006)

6 Calanna S, Christensen M, Holst JJ, Laferrère B, Gluud LL, Vilsbøll T \& Knop FK. Secretion of glucagon-like peptide-1 in patients with type 2 diabetes mellitus: systematic review and meta-analyses of clinical studies. Diabetologia 201356 965-972. (doi:10.1007/s00125013-2841-0)

7 Højberg PV, Vilsbøll T, Zander M, Knop FK, Krarup T, Vølund A, Holst JJ $\&$ Madsbad S. Four weeks of near-normalization of blood glucose has no effect on postprandial GLP-1 and GIP secretion, but augments pancreatic B-cell responsiveness to a meal in patients with type 2 diabetes. Diabetic Medicine 200825 1268-1275. (doi:10.1111/j.14645491.2008.02579.x)

8 Toft-Nielsen MB, Madsbad S \& Holst JJ. Determinants of the effectiveness of glucagon-like peptide-1 in type 2 diabetes. Journal of Clinical Endocrinology and Metabolism 200186 3853-3860. (doi:10.1210/ jcem.86.8.7743)

9 Vilsbøll T, Krarup T, Deacon CF, Madsbad S \& Holst JJ. Reduced postprandial concentrations of intact biologically active glucagon-like peptide 1 in type 2 diabetic patients. Diabetes 200150 609-613. (doi:10.2337/diabetes.50.3.609)

10 Vilsbøll T, Krarup T, Madsbad S \& Holst JJ. Both GLP-1 and GIP are insulinotropic at basal and postprandial glucose levels and contribute nearly equally to the incretin effect of a meal in healthy subjects. Regulatory Peptides 2003114 115-121. (doi:10.1016/S01670115(03)00111-3)

11 Fukase N, Manaka H, Sugiyama K, Takahashi H, Igarashi M, Daimon M, Yamatani K, Tominaga M \& Sasaki H. Response of truncated glucagonlike peptide-1 and gastric inhibitory polypeptide to glucose ingestion in non-insulin dependent diabetes mellitus. Effect of sulfonylurea therapy. Acta Diabetologia 199532 165-169. (doi:10.1007/BF00838486)

12 Knop FK, Vilsbøll T, Højberg PV, Larsen S, Madsbad S, Vølund A, Holst JJ \& Krarup T. Reduced incretin effect in type 2 diabetes: cause or consequence of the diabetic state? Diabetes 200756 1951-1959. (doi:10.2337/db07-0100)

13 Knop FK, Vilsbøll T, Madsbad S, Holst JJ \& Krarup T. Inappropriate suppression of glucagon during OGTT but not during isoglycaemic i.v. glucose infusion contributes to the reduced incretin effect in type 2 diabetes mellitus. Diabetologia 200750 797-805. (doi:10.1007/ s00125-006-0566-z)

14 Orskov C, Jeppesen J, Madsbad S \& Holst JJ. Proglucagon products in plasma of noninsulin-dependent diabetics and nondiabetic controls in the fasting state and after oral glucose and intravenous arginine. Journal of Clinical Investigation 199187 415-423. (doi:10.1172/ JCI115012)

15 Theodorakis MJ, Carlson O, Michopoulos S, Doyle ME, Juhaszova M, Petraki K \& Egan JM. Human duodenal enteroendocrine cells: source of both incretin peptides, GLP-1 and GIP. American Journal of Physiology.
Endocrinology and Metabolism 2006290 E550-E559. (doi:10.1152/ ajpendo.00326.2004)

16 Vollmer K, Holst JJ, Baller B, Ellrichmann M, Nauck MA, Schmidt WE \& Meier JJ. Predictors of incretin concentrations in subjects with normal, impaired, and diabetic glucose tolerance. Diabetes 200857 678-687. (doi:10.2337/db07-1124)

17 Pazzi P, Scagliarini R, Gamberini S \& Pezzoli A. Review article: Gall-bladder motor function in diabetes mellitus. Alimentary Pharmacology \& Therapeutics 200014 62-65. (doi:10.1046/j.1365-2036. 2000.014s2062.x)

18 Shaw SJ, Hajnal F, Lebovitz Y, Ralls P, Bauer M, Valenzuela J \& Zeidler A. Gallbladder dysfunction in diabetes mellitus. Digestive Diseases and Sciences 199338 490-496. (doi:10.1007/BF01316504)

19 Stone BG, Gavaler JS, Belle SH, Shreiner DP, Peleman RR, Sarva RP, Yingvorapant N \& Van Thiel DH. Impairment of gallbladder emptying in diabetes mellitus. Gastroenterology 198895 170-176.

20 Güliter S, Yilmaz S \& Karakan T. Evaluation of gallbladder volume and motility in non-insulin-dependent diabetes mellitus patients using real-time ultrasonography. Journal of Clinical Gastroenterology 200337 288-291. (doi:10.1097/00004836-200310000-00005)

21 Bucceri AM, Calogero AE \& Brogna A. Gallbladder and gastric emptying: relationship to cholecystokininemia in diabetics. European Journal of Internal Medicine 200213 123-128. (doi:10.1016/S09536205(02)00003-1)

22 Knop FK. Bile-induced secretion of glucagon-like peptide-1: pathophysiological implications in type 2 diabetes? American Journal of Physiology. Endocrinology and Metabolism 2010299 E10-E13. (doi:10.1152/ajpendo.00137.2010)

23 Stone BG, Ansel HJ, Peterson FJ \& Gebhard RL. Gallbladder emptying stimuli in obese and normal-weight subjects. Hepatology $1992 \mathbf{1 5}$ 795-798. (doi:10.1002/hep.1840150508)

24 Dodds WJ, Groh WJ, Darweesh RM, Lawson TL, Kishk SM \& Kern MK. Sonographic measurement of gallbladder volume. American Journal of Roentgenology 1985145 1009-1011. (doi:10.2214/ajr.145.5.1009)

25 Everson GT, Braverman DZ, Johnson ML \& Kern F. A critical evaluation of real-time ultrasonography for the study of gallbladder volume and contraction. Gastroenterology 198079 40-46.

26 Krarup T \& Holst JJ. The heterogeneity of gastric inhibitory polypeptide in porcine and human gastrointestinal mucosa evaluated with five different antisera. Regulatory Peptides 19849 35-46. (doi:10.1016/ 0167-0115(84)90005-3)

27 Orskov C, Rabenhøj L, Wettergren A, Kofod H \& Holst JJ. Tissue and plasma concentrations of amidated and glycine-extended glucagonlike peptide I in humans. Diabetes 199443 535-539. (doi:10.2337/ diab.43.4.535)

28 Rehfeld JF. Accurate measurement of cholecystokinin in plasma. Clinical Chemistry 199844 991-1001.

29 Stadil F \& Rehfeld JF. Determination of gastrin in serum. An evaluation of the reliability of a radioimmunoassay. Scandinavian Journal of Gastroenterology 19738 101-112.

30 Medhus AW, Lofthus CM, Bredesen J \& Husebye E. Gastric emptying: the validity of the paracetamol absorption test adjusted for individual pharmacokinetics. Neurogastroenterology and Motility 200113 179-185. (doi:10.1046/j.1365-2982.2001.00249.x)

31 Miceli JN, Aravind MK, Cohen SN \& Done AK. Simultaneous measurements of acetaminophen and salicylate in plasma by liquid chromatography. Clinical Chemistry 197925 1002-1004.

32 Sonne DP, Hare KJ, Martens P, Rehfeld JF, Holst JJ, Vilsbøll T \& Knop FK. Postprandial gut hormone responses and glucose metabolism in cholecystectomized patients. American Journal of Physiology. Gastrointestinal and Liver Physiology 2013304 G413-G419. (doi:10.1152/ajpgi.00435.2012)

33 Lindgren O, Carr RD, Holst JJ, Deacon CF \& Ahrén B. Dissociated incretin hormone response to protein versus fat ingestion in obese subjects. Diabetes, Obesity \& Metabolism 201113 863-865. (doi:10.1111/ j.1463-1326.2011.01420.x) 
34 Carr RD, Larsen MO, Winzell MS, Jelic K, Lindgren O, Deacon CF \& Ahrén $B$. Incretin and islet hormonal responses to fat and protein ingestion in healthy men. American Journal of Physiology. Endocrinology and Metabolism 2008295 E779-E784. (doi:10.1152/ajpendo.90233.2008)

35 Alssema M, Rijkelijkhuizen JM, Holst JJ, Teerlink T, Scheffer PG, Eekhoff EM, Gastaldelli A, Mari A, Hart LM, Nijpels G et al. Preserved GLP-1 and exaggerated GIP secretion in type 2 diabetes and relationships with triglycerides and ALT. European Journal of Endocrinology 2013169 421-430. (doi:10.1530/EJE-13-0487)

36 Migoya EM, Bergeron R, Miller JL, Snyder RN, Tanen M, Hilliard D, Weiss B, Larson P, Gutierrez M, Jiang G et al. Dipeptidyl peptidase-4 inhibitors administered in combination with metformin result in an additive increase in the plasma concentration of active GLP-1. Clinical Pharmacology and Therapeutics 201088 801-808. (doi:10.1038/clpt.2010.184)

37 Matikainen N, Bogl LH, Hakkarainen A, Lundbom J, Lundbom N, Kaprio J, Rissanen A, Holst JJ \& Pietiläinen KH. GLP-1 responses are heritable and blunted in acquired obesity with high liver fat and insulin resistance. Diabetes Care 201437 242-251. (doi:10.2337/dc13-1283)

38 Kjems LL, Holst JJ, Vølund A \& Madsbad S. The influence of GLP-1 on glucose-stimulated insulin secretion: effects on $\beta$-cell sensitivity in type 2 and nondiabetic subjects. Diabetes 200352 380-386. (doi:10.2337/ diabetes.52.2.380)

39 Lindgren O, Carr RD, Deacon CF, Holst JJ, Pacini G, Mari A \& Ahrén B. Incretin hormone and insulin responses to oral versus intravenous lipid administration in humans. Journal of Clinical Endocrinology and Metabolism 201196 2519-2524. (doi:10.1210/jc.2011-0266)

40 Nilsson M, Holst JJ \& Björck IM. Metabolic effects of amino acid mixtures and whey protein in healthy subjects: studies using glucose-equivalent drinks. American Journal of Clinical Nutrition $2007 \mathbf{8 5}$ 996-1004.

41 Fieseler P, Bridenbaugh S, Nustede R, Martell J, Orskov C, Holst JJ \& Nauck MA. Physiological augmentation of amino acid-induced insulin secretion by GIP and GLP-I but not by CCK-8. American Journal of Physiology 1995268 E949-E955.
42 Boden G. Nutritional effects of fat on carbohydrate metabolism. Baillière's Clinical Endocrinology and Metabolism 200317 399-410.

43 Ahrén B, Holst JJ \& Deacon CF. An incretin effect exists after amino acids administration in humans; effects on incretin hormones and insulin after oral vs intravenous amino acids [abstract]. Diabetes 2014 64 (Suppl 1) 189-OR.

44 Dunning BE, Foley JE \& Ahrén B. Alpha cell function in health and disease: influence of glucagon-like peptide-1. Diabetologia $2005 \mathbf{4 8}$ 1700-1713. (doi:10.1007/s00125-005-1878-0)

45 Keshavrzzian A, Dunne M \& Iber FL. Gallbladder volume and emptying in insulin-requiring male diabetics. Digestive Diseases and Sciences 1987 32 824-828. (doi:10.1007/BF01296703)

46 De Boer SY, Masclee AA, Jebbink MC, Schipper J, Lemkes HH, Jansen JB $\&$ Lamers CB. Effect of acute hyperglycaemia on gallbladder contraction induced by cholecystokinin in humans. Gut 199334 1128-1132. (doi:10.1136/gut.34.8.1128)

47 Rayner CK, Samsom M, Jones KL \& Horowitz M. Relationships of upper gastrointestinal motor and sensory function with glycemic control. Diabetes Care 200124 371-381. (doi:10.2337/diacare.24.2.371)

48 De Boer SY, Masclee AA, Lam WF, Jansen JB \& Lamers CB. Effect of intravenous glucose on intravenous amino acid-induced gallbladder contraction and CCK secretion. Digestive Diseases and Sciences 199439 268-274. (doi:10.1007/BF02090196)

49 Gielkens HA, Lam WF, Coenraad M, Frölich M, van Oostayen JA, Lamers CB \& Masclee AA. Effect of insulin on basal and cholecystokinin-stimulated gallbladder motility in humans. Journal of Hepatology 199828 595-602. (doi:10.1016/S0168-8278(98) 80282-1)

50 Rushakoff RA, Goldfine ID, Beccaria LJ, Mathur A, Brand RJ \& Liddle RA. Reduced postprandial cholecystokinin (CCK) secretion in patients with noninsulin-dependent diabetes mellitus: evidence for a role for CCK in regulating postprandial hyperglycemia. Journal of Clinical Endocrinology and Metabolism 199376 489-493.

Received 16 April 2014

Revised version received 25 June 2014

Accepted 1 July 2014 